\title{
BOYA ÖZELLİKLERİNİN RADAR ABSORPSİYON KAPASİTESİNE ETKİSI
}

\author{
Gülsün AKTAŞ, Ali Rıza AKTAŞ, Metin GÜRÜ \\ Gazi Üniversitesi, Mühendislik Fakültesi, Kimya Mühendisliği Bölümü, 06570, Maltepe, Ankara \\ gulsunselimoglu@yahoo.com, aktas.ar@gmail.com, mguru@gazi.edu.tr
}

(Geliş/Received: 15.11.2014; Kabul/Accepted: 09.10.2015)

ÖZET

Radar absorpsiyon malzemeleri (RAM); radar tarafindan gönderilen elektromanyetik dalganın bir kısmını soğurarak malzemenin radarda tespitini güçleştiren malzemelerdir. Yapılan çalışmada; boya özelliklerinden bağlayıcı türünün ve boya kalınlığının demir esaslı pigment kullanılarak hazırlanan RAM üzerindeki etkileri araştııılmıştır. Çalışmanın amacı; hem yüksek sıcaklık dayanımı olan hem de uluslararası standartlarda RAM olarak kullanılabilecek boya üretmektir. En uygun bağlayıcının tespit edilmesinde hem sıcaklık dayanımı hem de absorpsiyon kapasitesi incelenmiştir. Demir esaslı pigmentin boya haline getirilebilmesinde yüksek sıcaklık dayanımı da amaçlandığı için silikon esaslı bağlayıcının kullanılmasına karar verilmiştir. Hazırlanan boya hem 18-40 GHz aralığında yaklaşık $-16 \mathrm{~dB}$ absorpsiyon yaptığı hem de $570^{\circ} \mathrm{C}$ 'a kadar özelliklerini koruduğu için yüksek sıcaklığa dayanıklı RAM olarak kullanılabileceği değerlendirilmiştir. Yapılan analiz neticesinde boya kalınlığının da uygulanacak yere göre seçilmesinin uygun olacă̆ tespit edilmiştir.

Anahtar Kelimeler: Demir esaslı RAM, yüksek sıcaklık dayanımı, curie sıcaklığı

\section{EFFECT OF PAINT PROPERTIES ON RADAR ABSORPTION CAPACITY}

\begin{abstract}
Radar absorption material (RAM); absorbs a portion of electromagnetic waves transmitted by radar and make it difficult to be detected by radar. In this study, paint properties, binder type and thickness of paint, impact on the iron based RAM were investigated. The aim of this study is to produce high temperature resistant paint which also counted as RAM in international standards. Both temperature resistant and absorption capacity were examined to determine most suitable binder for iron based RAM paint. Because of high temperature resistance most suitable binder was chosen as silicon based binder. Produced paint absorbs $-16 \mathrm{~dB}$ at $18-40$ frequency bands as well as resistant to $570^{\circ} \mathrm{C}$, so it was evaluated as high temperature resistant RAM. According to the analysis results; appropriate paint thickness should be chosen according to the application area.
\end{abstract}

Keywords: Iron based RAM, high temperature resistance, curie temperature

\section{GİRISS (INTRODUCTION)}

Savunma sanayinde diğer ülkelerin kullandı̆̆ cihazlara rakip olabilecek ve daha önemlisi onların cihazlarını devre dışı bırakabilecek teknolojilerin geliştirilmesi her geçen gün daha da önem kazanmaktadır. Savunma sanayinde kullanılan en önemli teknolojilerden birisinin de radar olduğu düşünülürse radara yakalanmayan malzemelerin üretimi tüm dünya ülkeleri için önem taşımaktadır. RAM (Radar Absorpsiyon Malzemesi) kullanarak malzemenin radarda tamamen görünmez yapılması mümkün değildir. Radarda RAM ile kaplanmayan bir platform büyüklügüüne göre belli mesafelerde tespit edilebilir. Ancak bu platform RAM ile kaplandığı zaman RAM'in absorplama kapasitesine, platformun şekline vb. faktörlere bağlı olarak bu platform radarda çok küçük görülebilir ve tespit mesafesi kısalabilir. Örneğin, bir hava aracı RAM ile kaplandığında radar tarafindan daha küçük bir nesne gibi algılanacaktır. $\mathrm{Bu}$ özellik sayesinde radar sistemine yakalanmadan ya da müdahale şansı vermeden askeri araçların istenilen hedefe en güvenli şekilde ulaşması sağlanmaktadır. Radar absorpsiyon malzemelerinin, 
absorpsiyon özelliği içeriğindeki ferromanyetik malzemelerden gelmektedir. Radar absorpsiyon malzemesi olarak değişik türdeki malzemeler kullanılabilmektedir. Karbon, metal ve metal parçacıkları, polipirol-polimer kompozitler ve polianilin RAM olarak kullanılan bazı bileşiklerdir [1]. Pigment kısmın üretiminde de farklı üretim yöntemleri kullanılabilmektedir; diffüzyon yöntemi [2], gaz fazı termal bozunma reaksiyonu [3], mekanokimyasal yöntem [4-10], kompozit malzeme hazırlama yöntemleri [11].

Absorpsiyon kapasitesinin dalga kılavuzu yöntemiyle ölçülebilmesi için toz halindeki RAM'in pigment kısmının kaplama haline getirilmesi gerekmektedir [12-17]. Caffarena ve diğ., demir oksit esaslı RAM üretiminde $\left(\mathrm{Ba}_{3} \mathrm{Co}_{0,9} \mathrm{Cu}_{1,1} \mathrm{Fe}_{24} \mathrm{O}_{41}\right)$ polikloropiren bağlayıcı olarak kullanmış olup ağırlıç̧a 80:20 oranında karıştırmış 3,0 mm kalınlıkta uygulamış ve maksimum absorpsiyonun 9,5 GHz'de $-22,5 \mathrm{~dB}$ olarak ölçmüşlerdir [12]. Caffarena'nın diğer bir çalışmasında ise; $\quad \mathrm{Ba}_{3} \mathrm{Co}_{1,3} \mathrm{Zn}_{0,3} \mathrm{Cu}_{0,4} \mathrm{Fe}_{24} \mathrm{O}_{41}$ sentezlenmiş ve bağlayıcı olarak polikloropiren (80:20 ağırlıkça) kullanılmış ve maksimum absorpsiyon 2,5 mm kalınlıktaki boyada X-bandında $15 \mathrm{~dB}$ olarak belirlemişlerdir [13]. Ma ve diğ., sentezlediği $\mathrm{Co}_{0,5} \mathrm{Zn}_{0,5} \mathrm{Fe}_{2} \mathrm{O}_{4}$ bileşiğini polianilin ile karıştırmış ve maksimum absorpsiyonun $2 \mathrm{~mm}$ kalınlıktaki uygulamada $13,8 \mathrm{GHz}$ 'de $-23 \mathrm{~dB}$ olduğunu tespit etmişlerdir [14]. Wu ve diğ., NiZn ferrit/Bamboo kömürü ile epoksiyi (70:30 ağırlıkça) karıștırmış ve maksimum absorpsiyonu $2 \mathrm{~mm}$ kalınlıktaki uygulamada $11 \mathrm{GHz}$ 'de $-11 \mathrm{~dB}$ olarak ölçmüşlerdir [15]. Chen ve diğ., tarafından $\mathrm{BaTiO}_{3}$ ile epoksiyi karıştırarak (60:40 ağırlıkça) üretilen RAM maksimum absorpsiyonu 2,8 $\mathrm{mm}$ kalınlıktaki uygulamada 18,38 GHz'de $-28,38 \mathrm{~dB}$ olarak gerçekleştirmiştir [16]. Luo ve diğ., $\mathrm{SrSm}_{0,3} \mathrm{Fe}_{11,7} \mathrm{O}_{19}$ ile polianilin karıştırarak (10:90 ağırlıkça) $3 \mathrm{~mm}$ kalınlıkta boya olarak uygulamış ve maksimum absorpsiyon $14,2 \quad \mathrm{GHz}$ 'de $\quad-26 \quad \mathrm{~dB}$ olarak ölçülmüşlerdir [17]. Toz halinde üretilen pigmentlerin RAM olarak kullanılmasında farklı birçok malzeme kullanılmaktadır; ancak yapılan literatür araştırmasında üretilen malzemelerin sıcaklık dayanımlarına ilişkin analizler verilmediği için boyaların sıcaklık dayanımları tespit edilememiştir. Yapılan bu çalışmada yüksek sıcaklık dayanımı olan RAM üretilmesi amaçlanmıştır; çünkü Amerika menşeli F-117 yarasa uçaklarda kullanılan radar absorpsiyon malzemeleri yüksek sicaklıklara dayanmadığı için egzozlarından çıkan gazlar soğutulduktan sonra atmosfere bırakılmaktadır. Hava araçlarında yüksek sıcaklığa dayanıklı RAM kullanımıyla ek soğutma ünitesine gerek kalmayacaktır. Ayrıca benzer şekilde yüksek sıcaklığa maruz kalan malzemelerde de (örneğin; obüs ve tank namlusunda) kullanım olanağı sağlanacaktır. Yüksek sıcaklık dayanımında en etkili parametreler; bağlayıcının sıcaklık dayanımı ve pigmentin sıcaklık dayanımı. Yüksek sıcaklık dayanımı olan RAM üretimi, farklı türlerdeki (silikon bağlayıcı, alkit bağlayıc1, epoksi bağlayıcı) bağlayıcı ile pigment etkileşimleri hem absorpsiyon özellikleri hem de boya özellikleri açısından değerlendirilerek optimize edilmiştir. Boya kalınlığı da radar absorpsiyon malzemelerinde önemli diğer bir parametredir. Boya kalınlığı, boya ağırlığını belirleyen en etkin parametredir. Dolayısıyla özellikle hava araçları gibi taşınabilir yükün kritik olduğu sistemler için bu parametrenin optimizasyonu hayati önem arz etmektedir. Yapılan literatür araştırması neticesinde RAM araştırmalarında boya kalınlıklarının 1,0 - 6,0 $\mathrm{mm}$ arasında değiştirildiği ancak optimum değerlerin 2,0 - 3,0 mm arasında olduğu tespit edilmiştir [12-17]. $\mathrm{Bu}$ nedenle, optimimum boya kalınlığı tespiti için boyanın 1,0 ve 3,0 mm olarak uygulanmasına karar verilmiştir. $\mathrm{Bu}$ çalışmada; üretilen radar absorpsiyon malzemesinin pigment olarak kullanıldığı yüksek sıcaklıklarda boya özelliklerinin soğurma kapasitesine etkilerinin araştırılması amaçlanmıştır.

\section{DENEYSEL YÖNTEM (EXPERIMENTAL METHOD)}

Radar absorpsiyon malzemeleri iki kısımdan oluşmaktadır; ferromanyetik özellikteki toz pigment kısmı ve bağlayıcı kısmı. Üretilen RAM'ın pigment kısmı demir esaslı malzeme [18] olup bağlayıcı kısmı optimize edilmiştir. Silikon bağlayıcı (SILRES KX), kısa yağlı alkit bağlayıcı (ALY-40) ve epoksi bağlayıcı (EFLR-0140 FC) Boyut Ltd. firmasından satın alınarak demir esaslı RAM boya haline getirilmiştir. Çalışma esnasında bağlayıcı/pigment oranı her bağlayıcı türü için sabit tutulmuş olup, boya yapımı için ağırlıça \%70 pigment (demir esaslı RAM), \%30 bağlayıcı karıştırılmıştır. Boya haline getirilen RAM'in uygulanabilmesi için ölçüm için kullanilan $0,8 \times 10 \times 25 \mathrm{~mm}$ boyutlarında 2025 alüminyum levhaların (boya kalınlığının etkisi analizinde kullanılan 1x55x55 mm boyutlarındaki plakalara da uygun ayrı bir kalıp yapılmıştır) içine birebir oturacağı kalıplar hazırlanarak dökme tekniğiyle boya hazırlanmıştır. Boyanın istenilen kalınlıkta olması kalıp yüksekliği ile sağlanmıştır. Örneğin; $2 \mathrm{~mm}$ kalınlığında bir boya isteniliyorsa kalıp yüksekliği $0,8 \times 10 \times 25 \mathrm{~mm}$ boyutlarındaki levha için 2,8 mm olarak ayarlanıp boya kalınlığı $2 \mathrm{~mm}$ 'de sabit tutulmuştur. Radar absorpsiyon kapasitelerinin ölçümünde kullanılan Maury marka dalga kılavuzları SPARK Ölçüm teknolojileri firmasından satın alınmıştır. Radar absorpsiyon malzemelerinin kullanılabileceği maksimum sıcaklığı etkileyen iki faktör mevcuttur; üretilen pigmentin Curie sicaklığı ve kullanılan bağlayıcının sıcaklık dayanımı. Pigment olarak kullanılan demir esaslı RAM'ın Curie sıcaklığı yapılan TGA-DSC analizinde belirlenmiştir. Curie sıcaklığı TQ500 marka TGA cihazı kullanılarak belirlenmiștir. Curie sicaklığı tespiti ASTM 
Designation E: 1582-93'e göre yapılmıştır [19]. Bu ölçüm yöntemi aslında TGA cihazının sicaklık kalibrasyonu için kullanılmaktadır. Malzeme manyetik alana yerleştirildiği zaman, mıknatıs onu kendine doğru çekerek ek bir ağırlık kazandırmaktadır. Ancak Curie sıcaklığına geldiği zaman malzeme paramanyetik olur ve miknatıs etkisi ile meydana gelen ağırlık sıfırlanmaktadır. Ağırlığın sıfirlandığı noktada kütlede ani bir düşüş gözlemlenmekte ve kütlede bu düşüşün meydana geldiği sıcaklık Curie sıcaklığı olarak tespit edilmektedir. Üretilen boyaların 1sıya duyarlılık testleri de PROTERM marka firında gerçekleştirilmiştir. $150^{\circ} \mathrm{C}, 250^{\circ} \mathrm{C}, 350^{\circ} \mathrm{C}, 500^{\circ} \mathrm{C}$ ve $700^{\circ} \mathrm{C}$ 'ye 1sitılarak üretilen boyaların 1sıya dayanımı analiz edilmiştir. Ayrıca $-24^{\circ} \mathrm{C}$ 'ye soğutularak da boyanın soğuk uygulamalardaki dayanımı test edilmiştir. $\quad-24^{\circ} \mathrm{C}$ 'deki dayanımı özellikle hava araçlarında uçuş esnasında maruz kalacağı sıcaklık değerlendirilerek test edilmiştir. Sıcaklık dayanımı, boyalarda herhangi bir çatlama, renk değişimi vb. fiziksel değişimlere göre incelenmiştir. Radar absorpsiyon malzemeleri için en önemli parametre olan absorplama kapasitesinin tespit edilmesinde 2 yöntem kullanılmıştır. Birinci yöntem olan dalga kılavuzu yöntemi en uygun boya kalınlığının optimizasyonunda kullanılmıştır. Dalga kılavuzu yöntemi laboratuvar ölçekli çalışmalar için daha uygundur. Bu yöntemde HP 6844 marka Mikrodalga Analiz (Microwave Analyzer) cihazı ve dalga kılavuzları (wave guide) kullanılmıştır. Analiz 12,4 $18,0 \mathrm{GHz}$ aralığında gerçekleştirilmiştir. Boya 0,8x10x25 mm boyutlarında 2025 alüminyum levhalara uygulanarak ölçümü yapılmıştır. Absorpsiyon kapasitesi ölçümlerinde S11 parametresi kullanılmıştır. S11 parametresi, gönderilen dalga ile gelen elektromanyetik dalga arasındaki güç kaybını onluk logaritma tabanı oranı şeklinde ifade edilmektedir. Uygun bağlayıcının belirlenmesinde; alkit esaslı bağlayıcı ile üretilen boyanın yüzeyinin çok parlak olması nedeniyle dalga kılavuzu ile yapılan ölçümler için çok uygun olmayacağı değerlendirilmiş olup boşluk uzay yöntemiyle absorpsiyon kapasiteleri ölçülmüştür. Bu nedenle; silikon esaslı bağlayıcı ve kısa yağlı alkit bağlayıcı ile boya yapılarak 1x55x55 $\mathrm{mm}$ boyutlarındaki plakalara uygulanmıştır. Boşluk uzay yönteminde $18-40 \mathrm{GHz}$ aralığında ölçüm yapılmıştır.

\section{DENEYSEL BULGULAR VE TARTIŞMA (EXPERIMENTAL RESULTS AND DISCUSSION)}

Üretilen boyanın özellikle hava araçlarında egzoz çıkış sıcaklığı gibi yüksek sıcaklıklara dayanıklı olması amaçlanmıştır. Ancak hava araçlarında boya olarak kullanılabilmesini etkilen önemli özelliklerden birisi de kaplamanın ağırlığıdır. Kaplama ağırlığını belirleyen en önemli kriter ise; boya kalınlığı olduğu için optimize edilmiştir. Optimizasyon için boya hazırlanırken ağırlıkça \%20 silikon esaslı bağlayıcı ile $\%$ demir esaslı pigment karıștırılarak boya hazırlanmıștır. Kalıplarda dökme yöntemiyle $1 \mathrm{~mm}$ ve $3 \mathrm{~mm}$ kalınlıklarında boya uygulaması yapılmış ve dalga k1lavuzu ile yapilan analiz neticesinde elde edilen absorpsiyon kapasitesi sonuçları Şekil 1'de verilmiştir. Şekil 1'den de görüldüğü üzere; düşük frekanslarda $3 \mathrm{~mm}$ kalınlığındaki boya daha iyi absorpsiyon yaparken orta frekanslarda iki boyada benzer değerlere ulaşmışlardır. Yüksek frekanslarda ise; $1 \mathrm{~mm}$ kalınlığındaki boya daha yüksek absorpsiyon kapasitesine sahiptir. Düşük frekanslarda; $1 \mathrm{~mm}$ kalınlığındaki boyanın düşük absorpsiyon kapasitesine sahip olmasının nedeninin; frekans azaldıkça manyetik dalga boyunun artmasıyla dalga boyanın daha derinine doğru gidip geri yansımaktadır. $\mathrm{Bu}$ nedenle de kalınlık düşük frekanslarda çalışılacaksa daha büyük önem arz etmektedir. Ayrıca

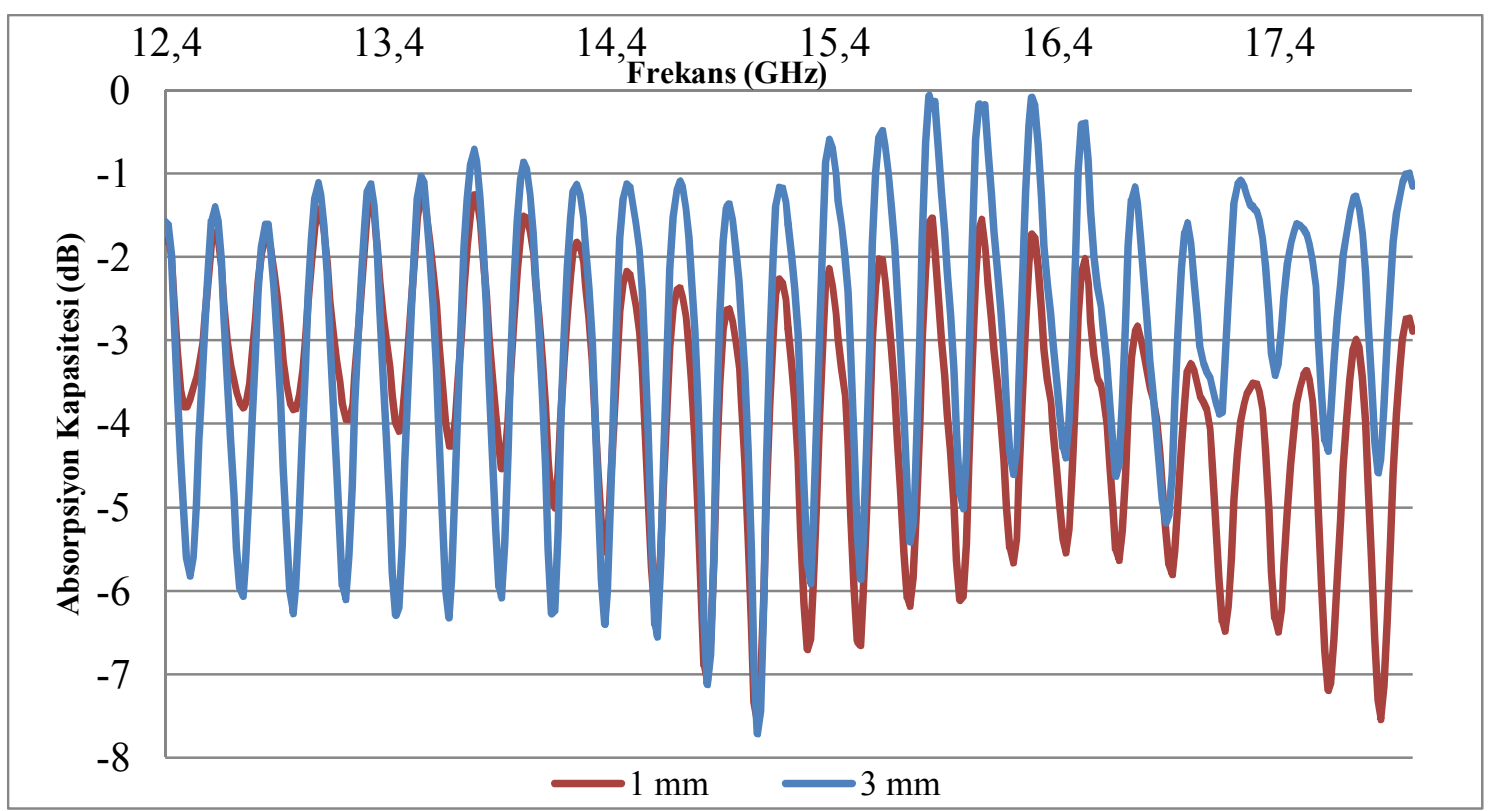

Şekil 1. Kalınlığın absorpsiyon kapasitesine etkisi (Effect of thickness on absorption capacity) 
kalınlık azalınca daha az miktarda ferromanyetik malzeme içermektedir ki bu da absorpsiyon kapasitesini azaltmıştır. Uygulanan $1 \mathrm{~mm}$ kalınlık diğer alanlardaki boya uygulamaları için kalın gibi görünmesine rağmen RAM uygulamaları için uygun hatta düşük bir kalınlık olduğu yapılan kaynak araştırmasından gözlenmiştir. Cao ve diğ., RAM uygulamalarında optimum boya kalınlığının belirlenmesi için genel dizayn kuralları ve formüllerinin olmadığını belirtmişlerdir [20]. Daha önce yapılan çalışmalarda ise; kaplama kalınlığ 1,0 $6,0 \mathrm{~mm}$ aralığında değiştirilmiş olmasına rağmen optimum kalınlık genellikle 2,0 - 3,0 mm olarak farklı tipteki radar absorpsiyon malzemeleri için belirlenmiştir [12-17]. Bu bilgiler doğrultusunda, kullanılacak boya kalınlığın uygulama alanı göz önüne alınarak karar verilmesinin daha uygun olacağı değerlendirilmiştir. Radar absorpsiyon malzemelerinin kullanılabileceği maksimum sicaklığ etkileyen iki faktör mevcuttur; üretilen pigmentin Curie sıcaklığı ve kullanılan bağlayıcının sıcaklık dayanımı. Şekil 2'den görüldüğü gibi, üretilen demir esaslı RAM'ın Curie sicaklığı TGA kullanılarak $570^{\circ} \mathrm{C}$ olarak tespit edilmiştir. Kullanılan bağlayıcıların sıcaklık dayanımlarını tespit edebilmek için silikon, alkit ve epoksi esaslı bağlayıcılar pigmentler ile boya haline getirilerek sicaklık dayanımları test edilmiş ve elde edilen sonuçlar Şekil 3-7'de verilmiştir. Elde edilen sonuçlara göre; $250^{\circ} \mathrm{C}$ 'den sonra epoksi esasl 1 boyanın, $350^{\circ} \mathrm{C}$ 'den sonra alkit esaslı boyanın ve $700^{\circ} \mathrm{C}$ 'den sonra da silikon esaslı boyaların bozunmaya başladığı ve bu sıcaklıkların üzerinde kullanılamayacağı gözlemlenmiştir. Zaten pigmentin (demir esaslı bileşiğin) ferromanyetik özelliği $570^{\circ} \mathrm{C}$ 'den sonra bozulduğu için yüksek sıcaklık dayanımı gereken yerlerde silikon esaslı boyanın kullanılmasının daha uygun olacağı değerlendirilmiştir. $350^{\circ} \mathrm{C}$ 'a kadar olan uygulama bölgelerinde ise alkit esaslı boya kullanılırken, epoksinin sıcaklık dayanımının çok az olması nedeniyle kullanılmamasının daha uygun olacağı değerlendirilmiştir. Özellikle hava araçları uçuş esnasında soğuk havaya maruz kalmaktadır. Bu nedenle negatif değerlerde de boyanın dayanımı incelenmiş olup $-24^{\circ} \mathrm{C}$ sicaklıkta da kaplamalarda herhangi bir bozunma olmadığı belirlenmiştir.

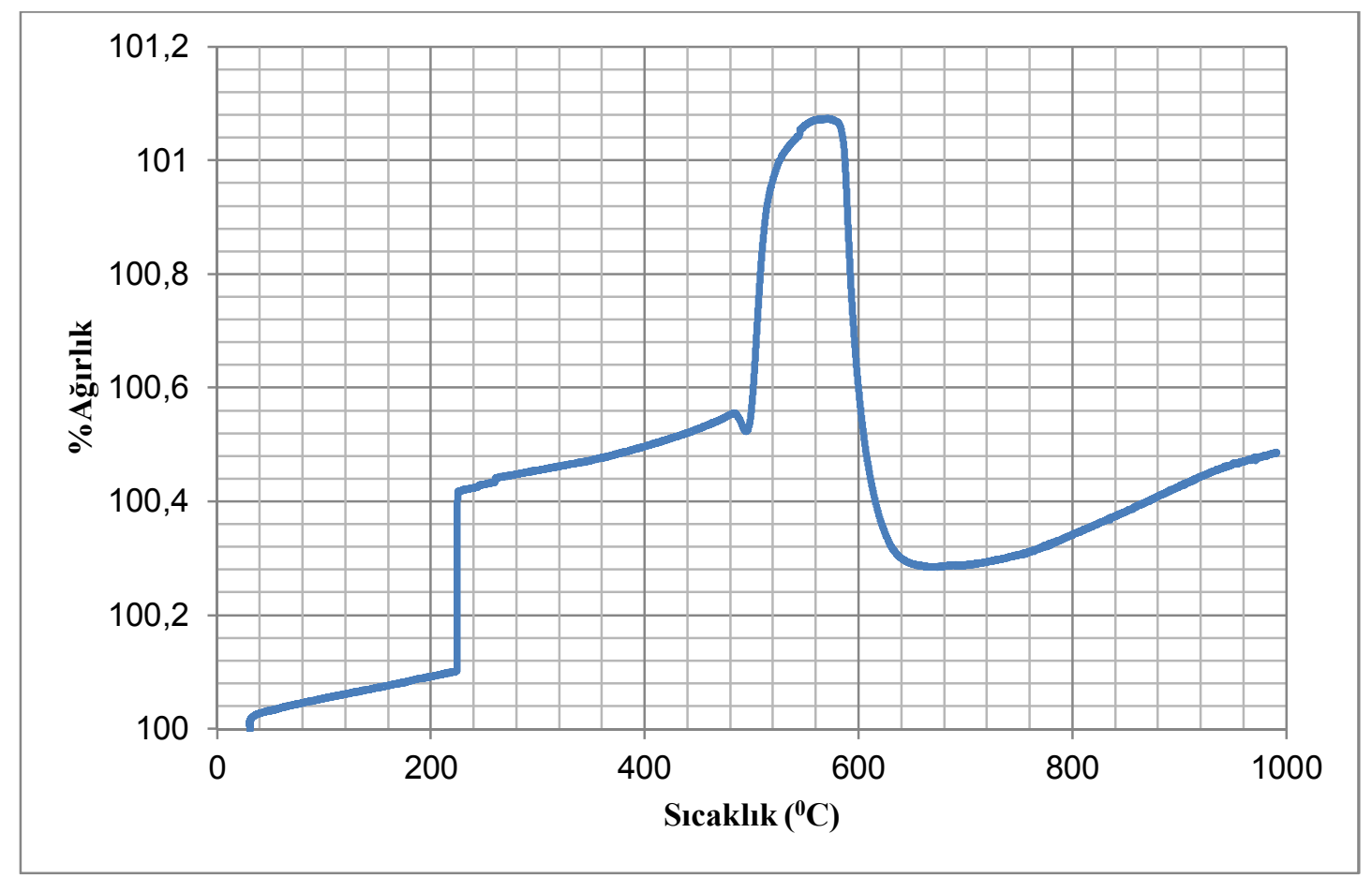

Şekil 2. Demir esaslı pigmentin Curie sıcaklığı (Curie temperature of iron based pigment)

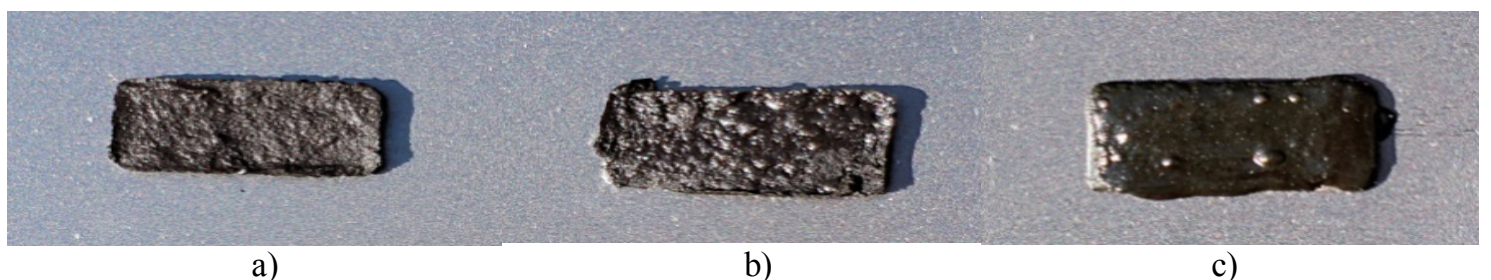

Şekil 3. $250^{\circ} \mathrm{C}$ 'de boyaların sıcaklık dayanımı a) silikon esaslı boya b) alkit esaslı boya c) epoksi esaslı boya (Heat resistance of paint at $250^{\circ} \mathrm{C}$ a) silicon based paint $b$ ) alkyd based paint c) epoxy based paint) 


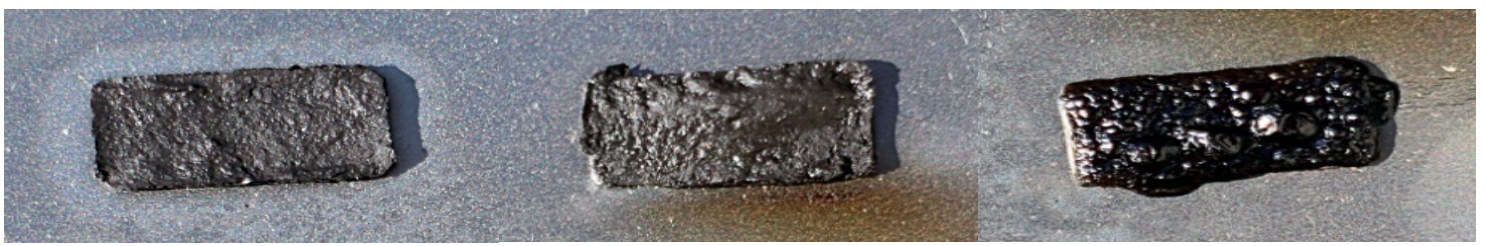

a) c)

Şekil 4. $350^{\circ} \mathrm{C}^{\prime}$ de boyaların sıcaklık dayanımı a) silikon esaslı boya b) alkit esaslı boya c) epoksi esaslı boya (heat resistance of paint at $350^{\circ} \mathrm{C}$ a) silicon based paint b) alkyd based paint c) epoxy based paint)

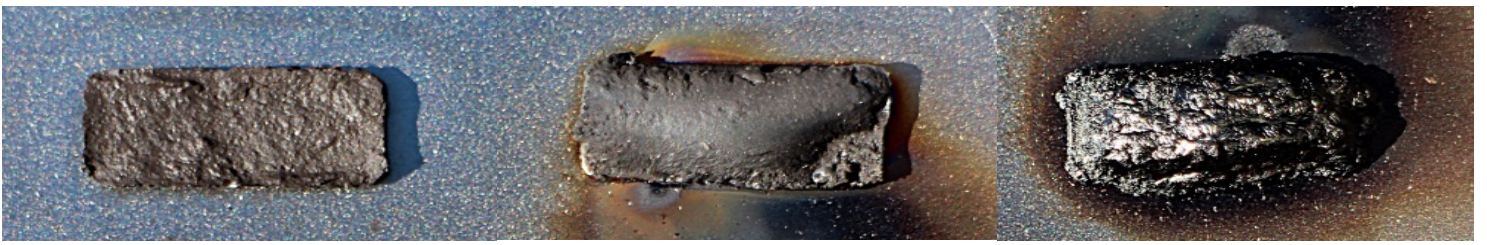

a) b) c)

Şekil 5. $500^{\circ} \mathrm{C}^{\prime}$ de boyaların sıcaklık dayanımı a) silikon esaslı boya b) alkit esaslı boya c) epoksi esaslı boya (heat resistance of paint at $500^{\circ} \mathrm{C}$ a) silicon based paint b) alkyd based paint c) epoxy based paint)

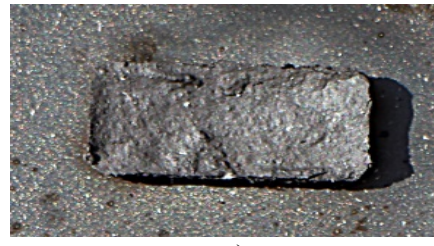

a)

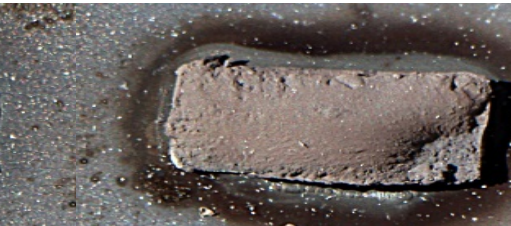

b)

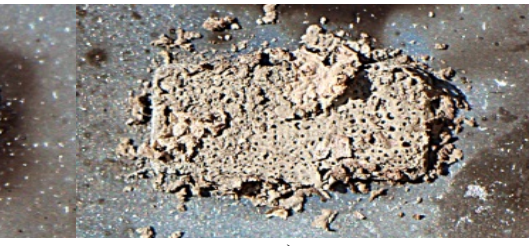

c)

Şekil 6. $700^{\circ} \mathrm{C}^{\prime}$ de boyaların sicaklık dayanımı a) silikon esaslı boya b) alkit esaslı boya c) epoksi esaslı boya (heat resistance of paint at $700^{\circ} \mathrm{C}$ a) silicon based paint b) alkyd based paint c) epoxy based paint)

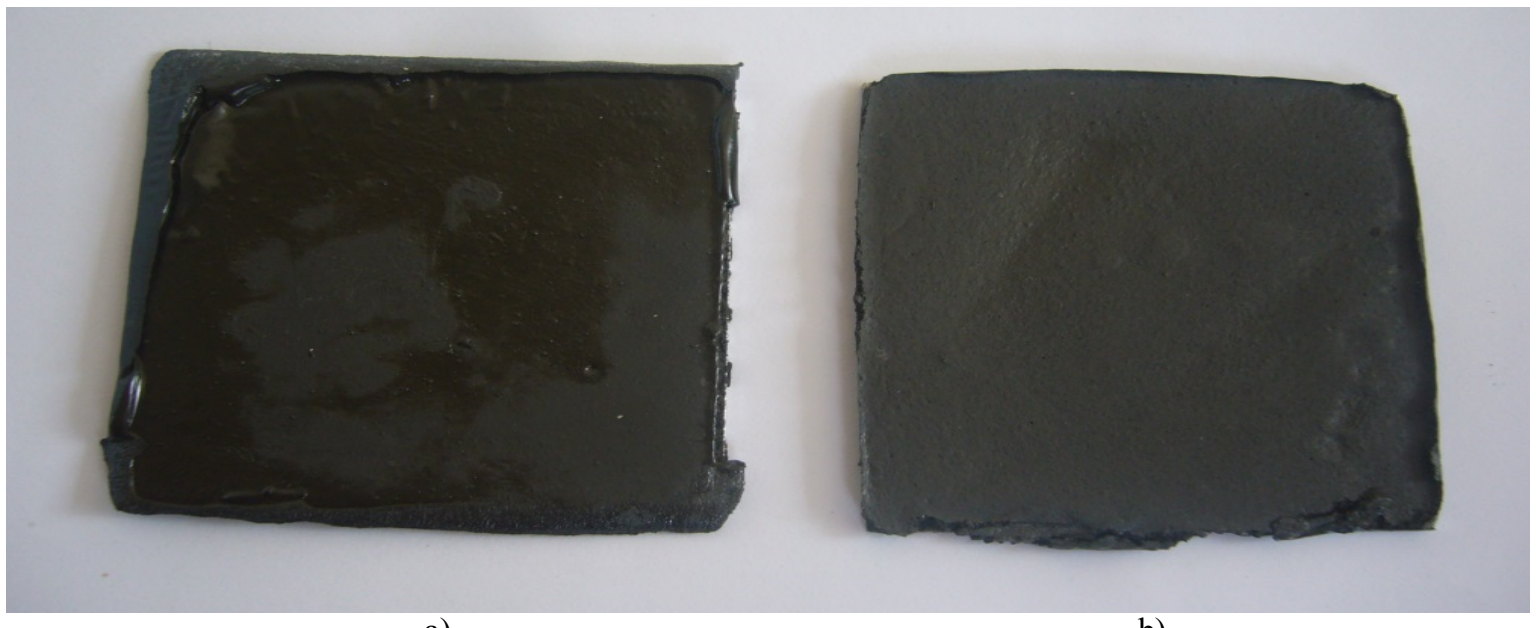

a)

b)

Şekil 7. $-24^{\circ} \mathrm{C}$ 'de boyaların sıcaklık dayanımı a) silikon esaslı boya b) alkit esaslı boya (heat resistance of paint at $-24^{\circ} \mathrm{C}$ a) silicon based paint b) alkyd based paint)

Sıcaklık dayanımı testinden sonra alkit ve silikon esaslı numunelerin RAM olarak kullanılabilirliğinin belirlenmesi için boşluk uzay yöntemiyle absorpsiyon kapasiteleri belirlenmiştir. Alkit reçine ile hazırlanan boya parlak olduğu için dalga kılavuzu yöntemi gibi kapalı ortamda ölçüm yapılan durumlarda parlaklık ekstra kırılma ve yansımalar yaratarak yanlış ölçüm sonuçlarının elde edilmesine neden olduğu için bu tür boyalarda kullanımı uygun değildir. Boşluk uzay yöntemi, dalga kılavuzu yöntemine göre gerçek ölçüme daha yakın bir ölçüm metodudur; çünkü atmosfer ortamında yapılmaktadır. Boşluk uzay yöntemine göre elde edilen absorpsiyon kapasitesi verileri Şekil 8'de verilmiştir. Boşluk uzay yöntemi ile yapılan analiz sonucunda; silikon esaslı bağlayıcı ile hazırlanan boyanin (\%70 pigment ve $2 \mathrm{~mm}$ kalınlıkta) boşluk uzay yöntemiyle 20,86 GHz'de$16,5 \mathrm{~dB}$ absorpsiyon kapasitesine sahip olduğu ve RAM olarak kullanılabileceği belirlenmiştir. Alkit esaslı bağlayıcı ile hazırlanan boyanın (\%70 pigment ve $2 \mathrm{~mm}$ kalınlıkta boya) boşluk uzay yöntemiyle 21,63 GHz'de $-13,72 \mathrm{~dB}$ absorpsiyon kapasitesine sahip olduğu ve RAM olarak kullanılabileceği belirlenmiştir. Silikon bağlayıcılı demir esaslı 


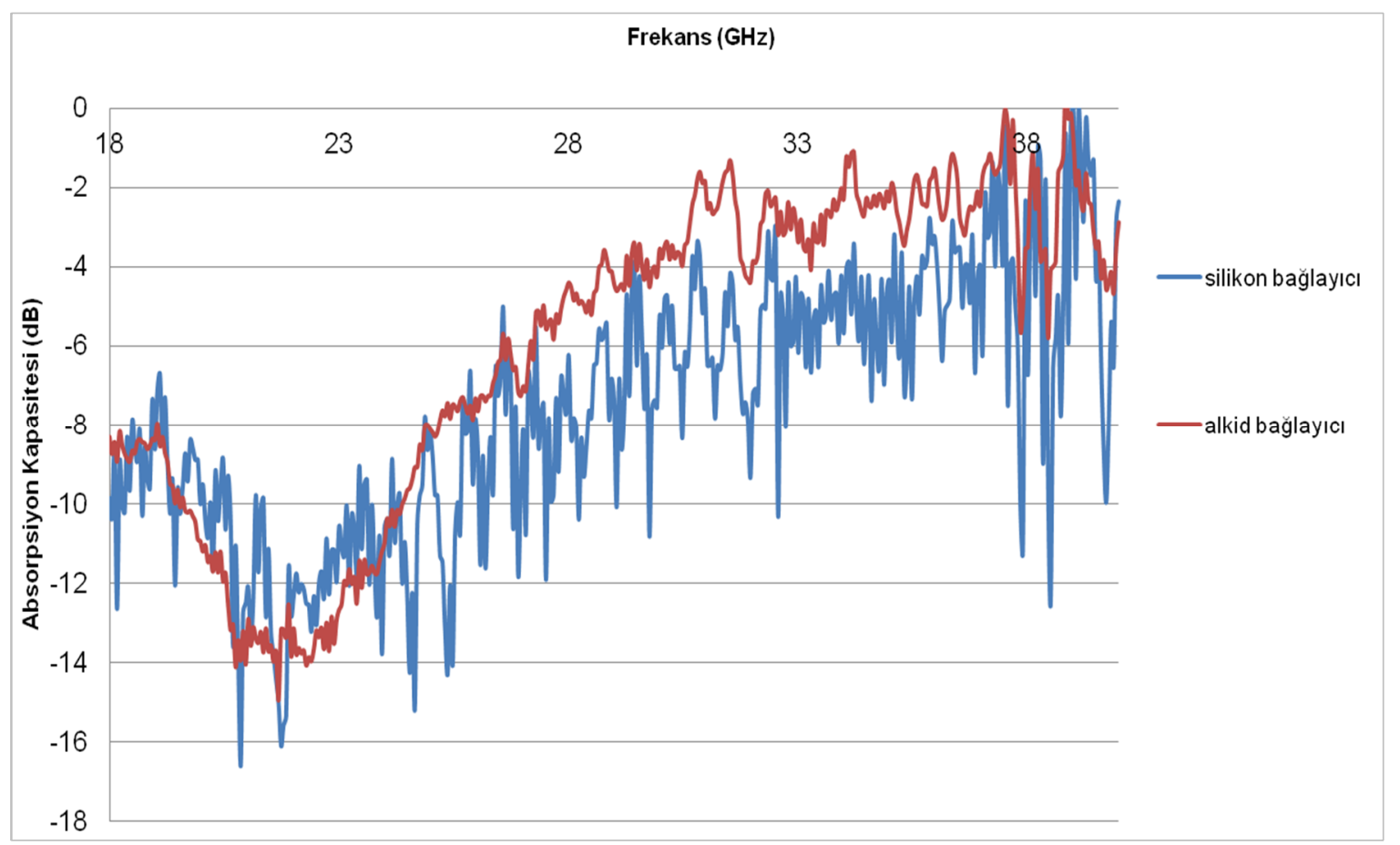

Şekil 8. Demir esaslı pigmentin absorpsiyon kapasitesine bağlayıcı türünün etkisi. (Effect of resin on the absorption capacity of iron based pigment)

RAM'ın alkit esaslı demir esaslı RAM'a göre daha iyi absorpsiyon yaptığı gözlemlenmiştir. Ancak; her iki boya da belirli frekans aralıklarında $-10 \mathrm{~dB}$ ve altında absorpsiyon yaptığı için her ikisinin de RAM olarak kullanılabileceği değerlendirmiştir. Radar absorpsiyon malzemeleri stratejik öneme haiz malzemeler olduğu için elde edilen bilgilerin makalelerde paylaşımı sinırlı miktarda olmaktadır. Mevcut makaleler ve patentlerde de çoğunlukla demir oksit esaslı radar absorpsiyon malzemelerinin pigment kısmının sentezlenmesine ve bileşiğin optimizasyonuna yönelik çalışmalar gerçekleştirilmiştir. Boya olarak hazırlanmasında üretilen pigmente yönelik kullanılabilecek bağlayıcı türlerinin optimizasyonu yapan başka bir makale tespit edilememiştir. Literatür araştırmasında silikon ve alkit esaslı bağlayıcı kullanımı tespit edilemediği için üretilen malzemelerin absorpsiyon kapasitelerinin karşılaştırılması uygun olmamaktadır. Bu çalışma ile hem farklı sıcaklıklar için kullanılabilecek yüksek sıcaklık dayanımı olan bağlayıcı belirlenmiştir hem de uygulama alanına göre uygulanması gereken boya kalınlığı tespit edilmiştir.

\section{SONUÇLAR (CONCLUSIONS)}

Yapılan çalıșmada bağlayıcı türünün ve boya kalınlığının radar absorpsiyon malzemesi uygulamalarına etkisi incelenmiştir. Yapılan deneysel çalışmalar neticesinde elde edilen sonuçlar aşağıda verilmiștir. Demir esaslı pigmentin yüksek sicaklık RAM uygulamaları için uygun bir bileşik olduğu yapılan Curie sıcaklığı tayini ile belirlenmiştir. Epoksi bağlayıcının sıcaklık dayanımı çok düşük $\left(<250^{\circ} \mathrm{C}\right)$ olduğu için RAM uygulamaları için uygun olmadığı için kullanılmamasının daha uygun olacağ1 değerlendirilmiştir. Gerek absorpsiyon kapasitesi gerekse sıcaklık dayanımı diğer bağlayıcı türlerine göre pigment ile daha iyi uyum sağladığından en uygun bağlayıcı türünün silikon esaslı bağlayıcı olduğuna karar verilmiştir. Oda sıcaklığının altında boyanın dayanımı özellikle hava araçlarındaki uygulamalar için test edilmiştir. Hava aracı uçarken düşük sicaklıklara maruz kalmaktadır. $\mathrm{Bu}$ nedenle düşük sıcaklık uygulamaları için $-24{ }^{\circ} \mathrm{C}$ 'e dayanımı alkit esaslı ve silikon esaslı boya için denenmiş olup her iki bağlayıcının da kullanılabileceği değerlendirilmiştir. Kaplama kalınlığının ise; frekans aralığına göre belirlenmesinin daha uygun olacağına karar verilmiştir. Uzaktaki bir cismin belirlenmesinde (Örneğin; helikopter, uçak vb.) düşük frekanslarda çalışan radarlar kullanıldığından buralarda daha kalın kaplama kullanılması daha uygun olacağı değerlendirilmiştir.

\section{TEŞEKKÜR (ACKNOWLEDGEMENT)}

$\mathrm{Bu}$ çalışma, Gazi Üniversitesi Bilimsel Araştırma Merkezi 06/2011-52 nolu proje ve TÜBİTAK Doktora Bursiyerlik programı tarafindan desteklenmiştir. Ayrıca boşluk uzay yöntemi analizlerinin yapılmasında yardımcı olan Doç. Dr. Arcan DERİCIOĞLU ve Yrd. Doç. Dr. Gül İpek SELİMOĞLU' na ve laboratuvar desteği sağlayan Prof. Dr. Tayfur ÖZTÜRK' e teşekkür ederiz. 


\section{KAYNAKLAR (REFERENCES)}

1. Saville, P., "Review of Radar Absorbing Materials", Defence R\&D Canada Technical Memorandum DRDC Atlantic TM 2005- 003, Kanada, 2-5, 2005.

2. Wiggins, E.W. and Drennan, D.N., "Corrosion Resistant RAM Powder”, United States Patent, Patent No 5,866,273, 1999.

3. Simon, J., Schlegel, R. and Leutner, B., "SiliconContaining Iron Powders", United States Patent, Patent No 5,993,569, 1999.

4. Golubkova, G.V., Lomovsky, O.I., Vlasov, A. A., Davlitova, L.S., Belyaev, E.Yu. and Malakhov, V. V., "Studies of X-ray Amorphous Phase in Mechanochemical Synthesis of Iron Silicides From Elements", Journal of Alloys and Compounds, 307, 131-136, 2000.

5. Kalita, M.P.C., Perumal, A. and Srinivasan, A., "Structure and Magnetic Properties of Nanocrystalline $\mathrm{Fe}_{75} \mathrm{Si}_{25}$ Powders Prepared by Mechanical Alloying", Journal of Magnetism and Magnetic Materials, Cilt 320 No 21, 27802783, 2008.

6. Stevulova, N., Buchal, A., Petrovič, P., Tkáčová , K. and Šepelák, V., "Structural Investigation of the High-Energy Milled Fe-Si System", Journal of Magnetism and Magnetic Materials, 203, 190-192, 1999.

7. Vélez G.Y., Rodríguez, R.R., Melo, C.A., Pérez Alcázar, G.A., Zamora, L.E. and Tabares, J. A., "Mössbauer and XRD Study of the $\mathrm{Fe}_{65} \mathrm{Si}_{35}$ Alloy Obtained by Mechanical Alloying", Hyperfine Interact, 203, 93-97, 2011.

8. Zuo, B. and Sritharan, T., "Ordering and Grain Growth in Nanocrystalline $\mathrm{Fe}_{75} \mathrm{Si}_{25}$ Alloy", Acta Materialia, 53, 1233-1239, 2005.

9. Yoo, Y.G., Yu, S.C. and Greneche, J.M., "The structural and Magnetic Properties of Fe-Si and Fe-C Solid Solutions as a Function of Milling Times", Journal of Materials Science, 39, 55235525, 2004.

10. Ding, J., Li, Y., Chen, L.F., Deng, C.R., Shi, Y., Chow, Y.S. and Gang, T.B., "Microstructure and Soft Magnetic Properties of Nanocrystalline FeSi Powders", Journal of Alloys and Compounds, 314, 262-267, 2001.

11. Gürer, G., "Design and Characterization of Electromagnetic Wave Absorbing Structural
Composites", Yüksek Lisans Tezi, Ortadoğu Teknik Üniversitesi, Ankara, 2001.

12. Caffarena, V.R., Capitaneo, J.L., Ogasawara, T. and Pinho, M.S., "Microwave Absorption Properties of $\mathrm{Co}, \mathrm{Cu}, \mathrm{Zn}$-Substituted Hexaferrite Polychloroprene Nanocomposites", Materials Research, 11, 335 -339, 2008.

13. Caffarena, V.R., Ogasawara, T., Pinho, M.S. and Capitaneo, J.L., "Synthesis and characterization of nanocrystalline $\mathrm{Ba}_{3} \mathrm{Co}_{0.9} \mathrm{Cu}_{1.1} \mathrm{Fe}_{24} \mathrm{O}_{41}$ powder and its application in the reduction of radar crosssection", Materials Science-Poland, Cilt 25, No 3, 875-884, 2007.

14. Ma, R.T., Zhao, H.T. and Zhang, G., "Preparation, characterization and microwave absorption properties of polyaniline $/ \mathrm{Co}_{0.5} \mathrm{Zn}_{0.5} \mathrm{Fe}_{2} \mathrm{O}_{4} \quad$ nanocomposite", Materials Research Bulletin, 45, 1064-1068, 2010.

15. $\mathrm{Wu}$, K.H., Ting, T.H., Liu, C.I., Yang, C.C. and Hsu, J.S., "Electromagnetic and microwave absorbing properties of $\mathrm{Ni}_{0.5} \mathrm{Zn}_{0.5} \mathrm{Fe}_{2} \mathrm{O}_{4} /$ bamboo charcoal core-shell nanocomposites", Composite Science and Technology, 68, 132-139, 2008.

16. Lihong Tian, L., Yan, X., Xu, J., Wallenmeyer, P., Murowchick, J., Liu, L. and Chen, X., "Effect of hydrogenation on the microwave absorption properties of BaTiO3 nanoparticles", Journal of Materials Chemistry A, 3 , 12250-12556, 2015.

17. Luo, J., Xu, Y. and Gao, D., "Synthesis, characterization and microwave absorption properties of polyaniline/Sm-doped strontium ferrite nanocomposite", Solid State Sciences, 37, 40-46,2014.

18. Gürü, M., Aktaş, G., Aktaş, A.R., "Demir Esaslı Radar Absorpsiyon Malzemesi Üretimi", İleri Teknolojiler Çalıştayı, İstanbul, 2012.

19. "Standard Practice for Calibration of Temperature Scale for Thermogravimetry", ASTM Standard E1582-93, 2000 Annual Book of ASTM Standards, Cilt 14, 01, American Society for Testing and Materials, West Conshohocken, 2000.

20. Cao, M., Qin, R., Qiu, C. and Zhu, J., "Matching Design and Mismatching Analysis towards Radar Absorbing Coatings Based on Conducting Plate", Materials and Design, 24, 391-396, 2003. 
